Andrew G. Clark FRCPC MBCHB, Mohamed Al-Qatari MD

\title{
Anaesthesia for Caesarean section in Takayasu's disease
}

Purpose: We present a case of Takayasu's Disease (Occlusive Thromboaortopathy - OTAP) in which general anaesthesia was used for Caesarean section with processed encephalographic monitoring to detect cerebral ischaemia.

Clinical features: The patient was a 33-year-old woman in whom OTAP had been the cause of cerebrovascular events. She had the typical pulseless upper body of OTAP and had documented severe bilateral carotid artery stenoses. Regional anaesthesia had failed in the past and she demanded general anaesthesia for Caesarean section. Processed electroencephalography was used to assist in monitoring for signs of cerebral ischaemia and the surgery was uncomplicated.

Conclusion: The use of processed electroencephalographic monitoring allows some assessment of cerebral haemodymamics during general anaesthesia in patients who refuse regional techniques.

Objectif : Présenter un cas de maladie de Takayasu (thromboaortopathie occlusive - TAPO) subissant une césarienne sous anesthésie générale avec monitoring encéphalographique informatisé pour détecter l'ischémie cérébrale.

Éléments cliniques : La patiente était âgée de 33 ans et la TAPO avait été la cause d'accidents cérébrovasculaires. Elle présentait l'absence de pouls typique dans la portion supérieure du corps et des sténoses bilatérales sévères des carotides avaient été documentées. Ayant connu un échec d'anesthésie régionale dans le passé elle désirait subir sa césarienne sous anesthésie générale. L'électro-encéphalographie informatisée a été utilisée pour détecter des signes d'ischémie cérébrale et la chirurgie s'est déroulée sans problème.

Conclusion : L'utilisation comme monitoring de l'électro-encéphalographie informatisée permet une certaine évaluation de l'hémodynamie cérébrale durant l'anesthésie générale chez des patients qui refusent l'anesthésie régionale. 
$\mathrm{T}$ AKAYASU'S Disease (Pulseless Disease, ${ }^{4}$ Occlusive Thromboaortopathy - OTAP $^{9}$ ) is a rare inflammatory panendarteritis causing thrombosis and occlusion of systemic and pulmonary arteries. Cerebrovascular ischaemia occurs in one third of patients ${ }^{1}$ making maintenance of cerebral blood flow vital. Eighty-five percent of cases involve young women. ${ }^{4,7}$ Oriental patients are the most common ethnic group. There have been limited reports of obstetric anaesthesia and of cerebral monitoring. We present a patient scheduled for Caesarean section under general anaesthesia in whom processed electroencephalographic monitoring was employed to assess cerebral perfusion.

\section{Case report}

A 33-yr-old Caucasian woman, $80 \mathrm{~kg}$ and $172 \mathrm{~cm}$, para 3 , gravida 4, with a diagnosis of OTAP made in 1987, presented for elective Caesarean section. She had chronic ischaemia of both arms, a minor stroke in 1994 and a series of transient ischaemic attacks, the last (amaurosis fugax) occurring six weeks before admission. Prednisone alleviated the arm ischaemia and, barring mild hypertension, the pregnancy was uncomplicated. She had no neurological ischaemia and transthoracic echocardiography showed normal ventricular function. Pulmonary, hepatic and renal function were normal. Obstetric assessment revealed no placental hypoperfusion or intrauterine growth retardation.

Evaluation of her airway showed no anticipated problems with tracheal intubation. Hyperextension of the neck produced transient dizziness thought to be due to traction on the vertebrobasilar vessels. ${ }^{7}$ Ultrasound evaluation of carotid arteries showed occlusion on the left and $98 \%$ stenosis on the right. She was dependent on the vertebro-basilar contribution to the circle of Willis for adequate perfusion.

The patient demanded general anaesthesia because epidural anaesthesia had been inadequate during her previous C-section and, when supplemental bupivacaine was given, she became weak, dyspnoeic and hypotensive. This necessitated tracheal intubation and general anaesthesia. She was too frightened to undergo epidural anaesthesia again.

We advised her that regional anaesthesia was our preference, both to avoid the hazards of intubation in the parturient, and also to enable simple monitoring of cerebral function (wakefulness, etc.) in patients with cerebrovascular disease. She remained unmoved, demanding general anaesthesia. We thus required a means of assessing cerebral perfusion and selected the Lifescan (Neurometrics, San Diego.CA) which processes the electroencephalogram to a compressed spectral array and displays the spectral edge frequency (SEF) simultaneously for each hemisphere. The SEF is the frequency below which is contained $96 \%$ of the EEG power. ${ }^{15}$ Unilateral depression of SEF has been shown to be a useful indication of ischaemia in carotid surgery ${ }^{2,11,12}$ and we felt, because of this patients anatomy, that it would serve our purpose. Accurate monitoring of blood pressure was planned using an intra arterial catheter in the normal dorsalis pedis artery, the radial being unavailable in OTAP.

Premedication with cimetidine and sodium citrate was followed by denitrogenation with oxygen $100 \%$ while standard monitors were applied, including five lead ECG, non-invasive BP cuff (over the thigh) and pulse oximeter to the toe. Left lateral tilt was used to prevent aortocaval compression and the five leads of Lifescan attached. Two 16-gauge iv lines and the arterial line were inserted under local anaesthesia. Blood pressure had increased to $220 / 130 \mathrm{mmHg}$ due to anxiety and anaesthesia was induced with $3 \mathrm{mg} \cdot \mathrm{kg}^{-1}$ propofol followed by $1.5 \mathrm{mg} \cdot \mathrm{kg}^{-1}$ succinylcholine $i$. The trachea was intubated under cricoid pressure and the $\mathrm{BP}$ and $\mathrm{HR}$ decreased to $150 / 85 \mathrm{mmHg}$ and $80 \mathrm{bpm}$ respectively. Anaesthesia was continued with nitrous oxide $60 \%$ in oxygen and isoflurane $0.7 \%$ endtidal until delivery of a healthy baby, six and a half minutes after skin incision. Oxytocin infusion began and anaesthesia was deepened using $4 \mathrm{mg}$ midazolam and $1000 \mu \mathrm{g}$ alfentanil: $0.3 \mathrm{mg} \cdot \mathrm{kg}^{-1}$ atracurium maintained neuromuscular relaxation.

The surgery went well, processed EEG showed no depression of SEF in either hemisphere. The anaesthetist involved had sufficient experience with Lifescan to allow appropriate interpretation of data. After skin closure, residual neuromuscular blockade was antagonised with $20 \mathrm{mg}$ pyridostigmine and $0.6 \mathrm{mg}$ glycopyrrolate. Awake extubation was performed. No problems occurred during the remainder of the hospital stay until discharge after five days.

\section{Discussion}

Ishikawa ${ }^{9}$ reported that, of 33 pregnant patients with OTAP, $60 \%$ had complications, usually hypertension worsening perinatally, with heart failure. The most serious problem was peripartum cerebral haemorrhage which proved fatal in three of the four patients affected. One third of patients delivered vaginally, one third had forceps (to prevent hypertensive surges with pushing) and one third had Caesarean section. There were no neonatal deaths.

Reports of anaesthesia in OTAP include spinal anaesthesia for therapeutic abortion ${ }^{5}$ and epidural anaesthesia for labour, ${ }^{4}$ Caesarean section, ${ }^{4}$ and tubal ligation. ${ }^{6}$ 
General anaesthesia without cerebral monitoring has been described for laparoscopic sterilisation and renal transplantation. ${ }^{8}$ Electroencephalographic monitoring, was used with general anaesthesia for abdominal aortic surgery, ${ }^{3}$ processed EEG was used in combined region$\mathrm{al} /$ general anaesthesia for hysterectomy $\mathrm{y}^{15}$ and transcranial Doppler in carotid endarterectomy. ${ }^{1}$

This report is of general anaesthesia for Caesarean section, using processed EEG monitoring as awake monitoring was unavailable. Since no changes were detected and no treatment was necessary, we cannot be sure that the technique was helpful, but its demonstrated usefulness in carotid surgery led us to believe that we would have been given an opportunity ${ }^{13}$ to treat ischaemia had it occurred when the patient was asleep.

Isoflurane ${ }^{12}$ and propofol $^{13}$ were used to help reduce cerebral oxygen requirements to levels which her compromised circulation could supply. We hoped to lessen the danger from unexpected hypotension. Isoflurane does not interfere with EEG diagnosis of ischaemia. ${ }^{15}$ Short acting opioid and relaxant drugs allowed rapid awakening and easy assessment of cerebral function. Cooperation between obstetrician, anaesthetist, neonatologist and the patient was crucial.

\section{Conclusion}

Regional anaesthesia remains a safe technique for Caesarean section and for patients, such as those with OTAP, in whom cerebrovascular disease mandates monitoring for ischaemia. However, when regional anaesthesia is prohibited, we suggest the use of processed EEG monitoring which, whilst not absolutely sensitive or specific, ${ }^{2}$ may be better than no monitor when the patient is asleep.

\section{References}

1 Kawaguchi $M$, Ohsumi $H$, Nakajima T, Kuro $M$. Intra-operative monitoring of cerebral haemodynamics in a patient with Takayasu's arteritis. Anaesthesia 1993; 48: 496-8.

2 Porter SS, Aker J. Electrophysiologic monitoring of the central nervous system. In: Porter SS (Ed.). Problems in Anesthesia. Neuroanesthesia, Vol 4. Philadelphia: J.B Lippincott Co., 1990: 32-40.

3 Warner MA, Hughes DR, Messick JM. Anesthetic management of a patient with pulseless disease. Anesth Analg 1983; 62: 532-5.

4 Beilin $\Upsilon$, Bernstein $H$. Successful epidural anaesthesia for a patient with Takayasu's arteritis presenting for Caesarean section. Can J Anaesth 1993; 40: 64-6.

5 Hampl KF, Schneider MC, Skarvan K, Bitzer J, Graber J. Spinal anaesthesia in a patient with Takayasu's disease. Br J Anaesth 1994; 72: 129-32.
6 McKay RSF, Dillard SR. Management of epidural anesthesia in a patient with Takayasu's disease. Anesth Analg 1992; 74: 297-9.

7 Ramanatban S, Gupta U, Cbalon J, Turndorf $H$. Anesthetic considerations in Takayasu arteritis. Anesth Analg $1979 ; 58:$ 247-9.

8 Thorburn JR, James MFM. Anaesthetic management of Takayasu's arteritis. Anaesthesia 1986; 41: 734-8.

9 Ishikawa $K$, Matsuura S. Occlusive thromboaortopathy (Takayasu's disease) and pregnancy. Clinical course and management of 33 pregnancies and deliveries. Am J Cardiol 1982; 50: 1293-300.

10 Sundt TM Jr, Sharbrough FW, Piepgras DG, Kearns TP, Messick JM Jr, O'Fallon WM. Correlation of cerebral blood flow and electroencephalographic changes during carotid endarterectomy. Mayo Clin Proc 1981; 56: 533-43.

11 Myers RR, Stockard J, Saidman LJ. Monitoring of cerebral perfusion during anesthesia by timecompressed Fourier analysis of the electroencephalogram. Stroke 1997; 8: 331-7.

12 Michenfelder JD, Sundt TM, Fode N, Sharbrough FW. Isoflurane when compared to enflurane and halothane decreases the frequency of cerebral ischemia during carotid endarterectomy. Anesthesiology 1987; 67: 336-40.

13 Hemmings HC Jr. Neuroprotection by sodium channel blockade and inhibition of glutamate release. In: Neuroprotection. A Society of Cardiovascular Anaesthesiologists Monograph. Williams and Wilkins 1997: 34-9.

14 Herrema I. Takayasu's disease and caesarean section. International Journal of Obstetric Anesthesia 1992; 1: 117-9.

15 Gozal $\Upsilon$, Ginosar $Y$, Gozal D. Combined general and epidural anesthesia for a patient with Takayasu's arteritis. Reg Anesth 1995; 20: 246-8. 